\title{
Integração internacional, ambiente de negócios e desempenho das firmas
}

\author{
International integration, business climate and firms' performance
}

Gilberto Joaquim Fraga*

\begin{abstract}
Resumo: A presente pesquisa busca analisar a relação entre integração internacional, ambiente de negócios e produtividade a partir de dados em nível de firmas do Brasil. Para tanto, são realizadas estimativas, a partir dos dados de 1802 firmas estrangeiras e domésticas. Os resultados indicam, principalmente, que firmas com participação estrangeira apresentam melhor desempenho em relação às firmas domésticas. E um melhor ambiente de negócios afeta positivamente o desempenho das empresas, em específico, as variáveis que representam facilitação de comércio internacional, logística e oferta de trabalho qualificado.
\end{abstract}

Palavras-chave: IED; Clima de negócios; Produtividade

\begin{abstract}
This paper aims to analyze the relationship between international integration, business environment and productivity by using a dataset at firm level from Brazil. The estimates were carried out using dataset of 1,802 foreign and domestic firms. The main results indicate that firms with foreign ownership have higher performance than local ones. In addition, a better business environment positively affects the enterprises' performance, mainly facilitating international trade, logistics and adequate labor supply.
\end{abstract}

Keywords: FDI; Business Climate; Productivity

JEL Code: F15; D24

\footnotetext{
* Professor adjunto do Departamento de Economia, Universidade Estadual de Maringá (UEM). E-mail: gjfraga@uem.br. ORCID: https://orcid.org/0000-0002-6320-3847. O autor agradece o apoio financeiro do CNPq (APQ-457620).
} 


\section{Introdução}

O investimento estrangeiro direto (IED) cresceu intensivamente nos últimos anos nos países da América Latina. Dentre estes, países como o Brasil registraram recordes nos influxos de IED. A respeito dos efeitos do IED nas economias, que às vezes são controversos para os países receptores, a evidência da literatura empírica sobre IED confirma que existem efeitos positivos tanto para as firmas locais quanto para os países em geral (DOLLAR et al., 2006). Em nível micro, por exemplo, os benefícios do IED surgem quando as firmas domésticas interagem com as firmas estrangeiras (ALFARO et al., 2004; JAVORCIK, 2004) e isso torna possível a transferência de conhecimento tecnológico e de processos. Em suma, existe uma percepção de que a ampliação da integração internacional pode contribuir para o crescimento econômico. Dentre os determinantes para atrair IED, vem ganhando destaque o ambiente de negócios ${ }^{1}$ no pretendente país anfitrião. A partir dos anos 2000, policy-makers e organizações multinacionais têm dado cada vez mais importância ao ambiente de negócios nos países em desenvolvimento. E um ambiente de negócios que funciona bem pode ser amplamente entendido como um ambiente em que a governança e as instituições funcionam ancorando o empreendedorismo e o bom funcionamento do mercado de forma a impulsionar o crescimento e desenvolvimento (HALLWARD-DRIEMEIER et al., 2006).

$\mathrm{Na}$ literatura recente, o clima de investimento tem atraído a atenção com estudos em nível macroeconômico (SEKKAT; VEGANZONES-VAROUDAKIS, 2007; CORCORAN; GUILLANDERS, 2014) e em nível microeconômico (DOLLAR et al., 2006; KINDA, 2010). Esses estudos analisaram países em desenvolvimento, mas a América Latina, por exemplo, foi considerada conjuntamente com quatro países apenas (Brasil, Honduras, Nicarágua e Peru) na pesquisa de Dollar et al. (2006). Entretanto, o estudo do impacto do ambiente de negócios no Brasil está em aberto e deve ser considerado para entender a amplitude dos efeitos dessas variáveis sobre o desempenho das firmas. A análise do ambiente de negócios desagregado é de suma importância para implementar políticas específicas de aumento da eficiência econômica; como argumentam HallwardDriemeier et al. (2006), as economias são heterogêneas e as análises agregadas não

\footnotetext{
${ }^{1}$ Alternativamente, "ambiente de negócios" pode ser considerado como sendo sinônimo para "clima de investimento".
} 
permitem saber quais fatores podem ser importantes dentro das fronteiras dos países.

Nesse cenário, a presente pesquisa tem como objetivo analisar os impactos da integração internacional e o ambiente de negócios sobre o desempenho das firmas. Para alcançar o objetivo proposto, aprofunda-se em uma amostra de 1.802 firmas em 15 localidades geográficas para avaliar a integração internacional e três potenciais obstáculos (infraestrutura física e financeira, e tempo de desembaraço das importações) relacionados à operação das firmas. Esta pesquisa pode contribuir ao destacar reformas que o país pode fazer como condição para melhorar o desempenho das firmas no Brasil.

Além desta introdução, o presente estudo está estruturado como segue: na seção segunda, é feita uma breve apresentação da literatura relacionada; na terceira seção, faz-se uma apresentação descritiva dos dados; na quarta seção, há as estimativas e análises dos resultados. Por fim, na quinta seção, são feitas as considerações finais.

\section{Literatura relacionada: ambiente de negócios, IED e desempenho econômico}

Nesta seção, busca-se apresentar um panorama da literatura relacionada visando compreender os desenvolvimentos recentes nesse campo. As pesquisas, em geral, analisam grupos de países, e os impactos de políticas podem ser específicos para cada país, principalmente no que se refere ao ambiente de negócios.

Para entender a dinâmica do desempenho de um "gigante" emergente, Hallward-Driemeier et al. (2006) analisaram a relação entre propriedade estrangeira, clima de investimento e desempenho das firmas chinesas. O estudo contemplou 1.500 firmas em diferentes cidades e setores. Os resultados indicam que tanto o status de propriedade estrangeira quanto as variáveis de clima de investimento podem afetar positivamente o desempenho das firmas. Wagner (2007) apresenta uma revisão dos estudos em nível de firmas relacionando integração internacional (exportações) e produtividade; segundo o autor, a área ainda precisa de mais estudos para países diferentes para ter consistência nas conclusões.

Em uma análise que considera fatores complementares ao IED, Alfaro et al. (2009) verificaram o efeito do IED sobre a produtividade dos países. Os autores confirmam que países com mercado financeiro bem desenvolvido podem 
obter ganhos de produtividade com a entrada de IED. Em perspectiva similar, Javorcik (2004) analisou o efeito do IED sobre a produtividade em nível de firmas da Lituânia, e os resultados mostram a existência de spillovers positivo e aumento de produtividade procedente do contato das firmas estrangeiras (IED) com as firmas domésticas.

A partir de dados em nível de firmas, Castellani e Perugia (2009) investigaram a relação entre produtividade e firmas multinacionais. Os autores argumentam que a produtividade das empresas com capital estrangeiro é diferente da firma local. Já Kinda, Plane e Varoudakis (2009) analisaram a relação do clima de investimento e desempenho da firma. Os resultados mostram que, na média, existe uma relação positiva entre as variáveis de clima de investimento e produtividade. A relação entre clima de negócios e desempenho das firmas foi analisado por Dethier et al. (2010), e os autores mostram que essa relação é positiva. Xu (2010) analisou a relação entre ambiente de negócios e desenvolvimento econômico, e, nesse tópico, o autor argumenta que os resultados ainda são heterogêneos.

Para entender a relação entre ambiente de negócios e produtividade das firmas, Kinda et al. (2011) analisaram o norte da África; e, conforme os resultados, um melhor clima de investimento pode contribuir com a produtividade. Sendo importante a qualidade da infraestrutura, a experiência e a educação da força de trabalho, além do custo e acesso a financiamento.

A partir de uma grande amostra com 118 países, Waldkirch (2015) confirma que as firmas com capital estrangeiro, na respectiva estrutura de capital, apresentam maior nível de produtividade. No entanto, o autor destaca a heterogeneidade existente entre regiões.

Borin e Mancini (2016) investigaram a relação entre IED (outflow) e desempenho econômico a partir de microdados em nível de empresas na Itália. Os autores estimaram a produtividade total dos fatores (PTF), como também usaram medidas alternativas como vendas totais, valor adicionado, emprego, capital per capita e salário médio para o setor industrial e de serviços. Os resultados indicam que, para a PTF e a maioria dos indicadores, o impacto do IED é positivo sobre o desempenho. 


\section{Dados e apresentação descritiva}

Os dados foram obtidos com o Banco Mundial (enterprise investment climate) para países em desenvolvimento. Essa base de dados é particularmente importante para os países da América Latina porque não existe outra base de dados que contemple variáveis sobre ambiente de negócio e integração econômica dos países da região com tal nível de desagregação ${ }^{2}$. O clima de investimento apresentado nessa pesquisa é baseado em uma grande e aleatória amostra de firmas em setores específicos espalhados por 15 regiões do Brasil (Tabela 1). Adicionalmente aos dados de clima de investimento, foram coletados dados sobre produção e características das firmas. A análise considera 1.802 firmas no ano de 2009, com informações sobre características das firmas e sobre o ambiente de negócio em cada local em que as firmas estão localizadas. Esse conjunto de dados contêm informações para mensurar o desempenho econômico das firmas, em termos de produtividade; apresenta dados de integração internacional com a parcela da participação estrangeira na estrutura do capital da firma - proxy para IED $^{3}$, também utiliza-se a parcela dos insumos que são importados (BAS, 2012), porque esse é um potencial canal de conexão externa. A variável dependente que representa o desempenho da firma é a produtividade do trabalho; adicionalmente são utilizadas a taxa de crescimento das vendas da empresa e a taxa de crescimento do emprego.

As variáveis que representam o ambiente de negócios ${ }^{4}$ incluem: i. Números de dias para desembaraço alfandegário (procedimentos burocráticos para exportar/importar); ii. Infraestrutura física: número de dias de estoque do insumo mais importante; iii. Infraestrutura financeira: \% dos empréstimos para capital de giro e investimentos obtidos com bancos comerciais, bancos públicos, instituições não financeiras (cooperativas, empresas de microcrédito, companhias de fomento). As variáveis de características das firmas são: idade da empresa, tamanho conforme $\mathrm{n}^{\mathrm{o}}$ de empregados (pequena, média e grande), e se possui integração internacional. A característica da região é controlada por meio da aglomeração de empresas estrangeiras por setor em cada local. As características não observáveis são captadas mediante o controle dos efeitos fixos. As variáveis foram obtidas de

\footnotetext{
2 A presente base de dados do Banco Mundial foi disponibilizada sob termos e condições de confidencialidade.

${ }^{3}$ A variável IED assume valor igual a um quando pelo menos $10 \%$ do capital da firma é estrangeiro, seguindo o conceito padrão de IED do FMI, e zero quando o contrário.

${ }^{4}$ Discussão detalhada sobre variáveis que representam clima de investimento ver, Dollar et al., (2006) e Kinda (2010).
} 
firmas situadas em 10 setores: têxtil, alimentos, metais e maquinários, químico e farmacêutico, madeira e móveis, vestuário, automóveis e componentes, e outras indústrias. As variáveis explicativas foram escolhidas pela relevância econômica e, também, pela quantidade de valores non-missing. A Tabela A1 do apêndice apresenta a notação e definição das variáveis.

Os principais obstáculos para operação das firmas no Brasil são apresentados na Figura 1. Quanto às variáveis, estas dividem-se em duas categorias: variáveis objetivas como tributos, que é a primeira variável indicada pela maioria das firmas $(31,33 \%)$; e subjetivas ${ }^{5}$ como práticas dos competidores informais, que é o segundo obstáculo mais citado pelas firmas (12.26\%). No outro extremo, obter licença para negócios é indicado por apenas $1,91 \%$ das firmas da amostra.

\section{Figura 1 - Distribuição das firmas (em \%) e os principais obstáculos}

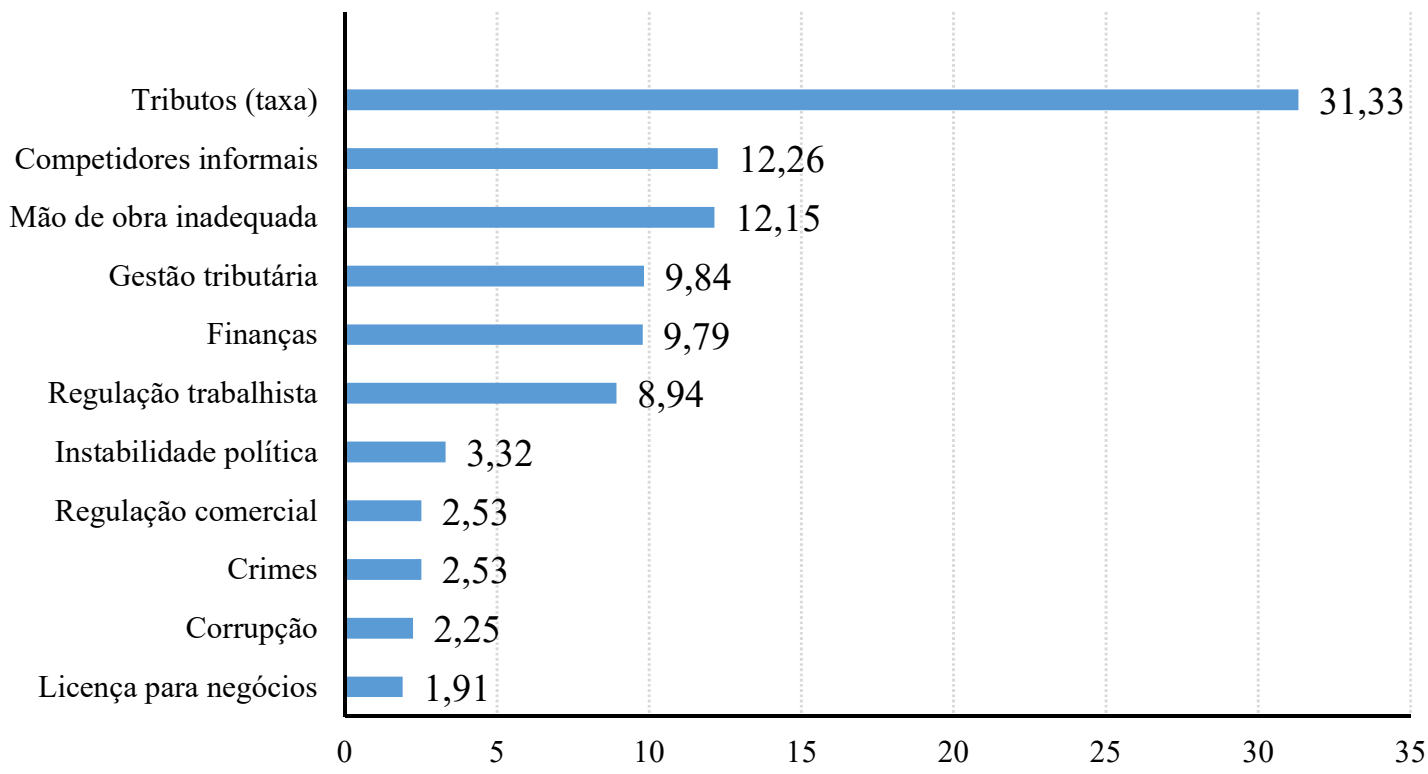

Fonte: Elaboração própria, dados da pesquisa (2017).

A distribuição das firmas da indústria de transformação, conforme o setor de atuação, é apresentada na Figura 2. Constata-se que não há uma grande disparidade na distribuição: enquanto $11,71 \%$ das firmas estão no setor de metais e maquinários, na outra ponta, 7,82\% das empresas entrevistas são dos setores

\footnotetext{
${ }^{5}$ Variáveis subjetivas são binárias ou categóricas e representam a opinião do executivo na empresa que foi entrevistada durante a realização da survey.
} 
químico/farmacêutico. O grupo dos setores industriais representa 75\% da amostra pesquisada, as demais empresas são dos setores de serviços.

\section{Figura 2 - Distribuição das firmas por setor (\%)}

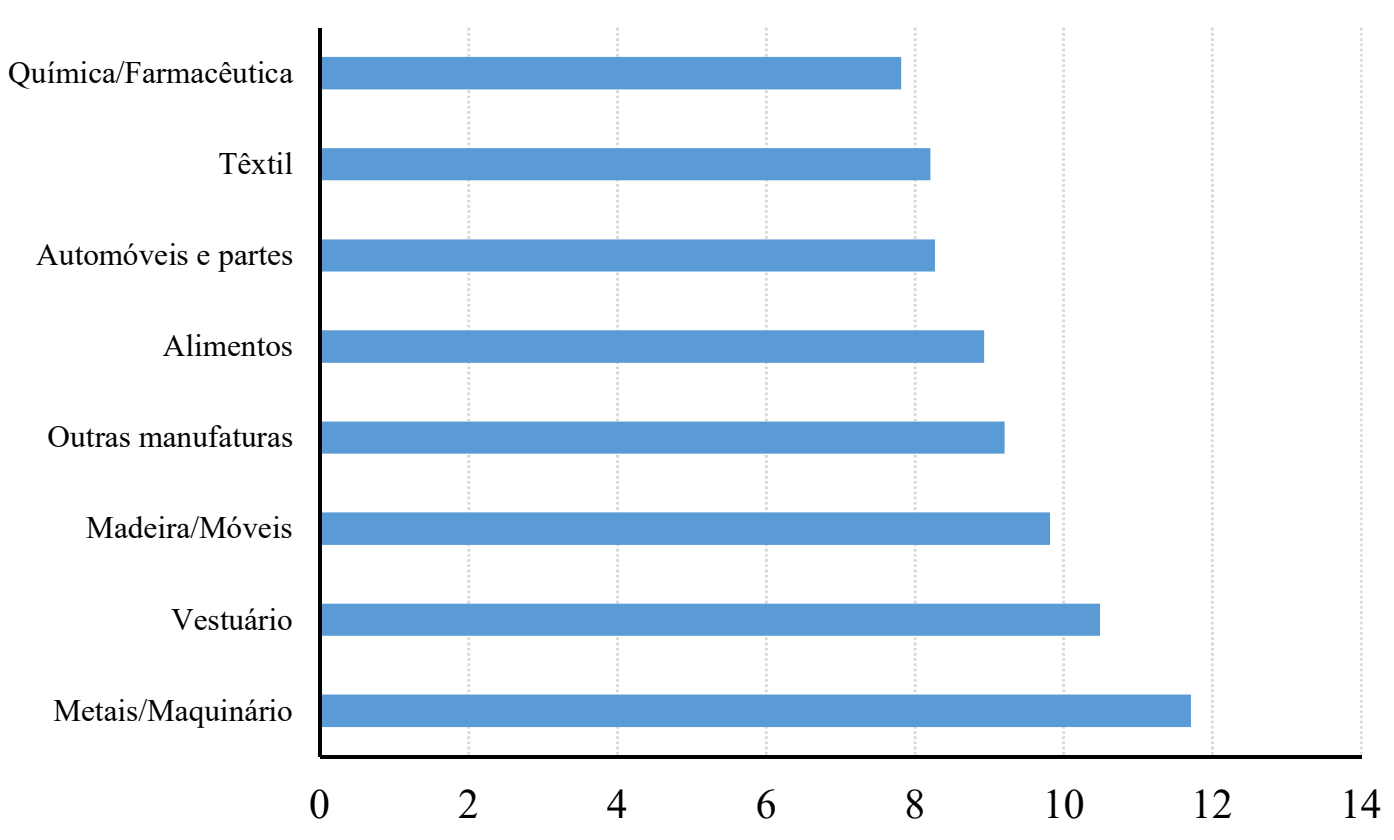

Fonte: Elaboração própria, dados da pesquisa (2017).

Quanto à distribuição das firmas por localidade, observa-se que, em São Paulo, estão localizadas $24,47 \%$ das firmas, esse percentual é 2,3 p.p. superior ao segundo colocado (Rio Grande do Sul) conforme Figura 3. Ainda, 73\% das firmas estão localizadas nas regiões Sudeste (exceto Espírito Santo) ou Sul. Por outro lado, os estados da Paraíba e Maranhão possuem menos de 1\% das firmas da amostra. São Paulo registrou também o maior nível de produtividade do trabalho (em Ln), sendo aproximadamente 5,8\% superior à média da amostra (anexo, Tabela A3). Vale ressaltar que, embora a maior parte das empresas escolham se localizar em São Paulo, o tempo médio (em \% do tempo total) que um diretor sênior gasta para resolver assuntos relacionados a procedimentos $\mathrm{e}$ regulamentações do governo - que é uma medida do ambiente de negócios - é $20 \%$ superior à média da amostra. Por outro lado, uma empresa localizada no estado gasta um tempo médio (em dias) para exportar inferior à média da amostra. 
Figura 3 - Distribuição (\%) das firmas por localidade (UF)

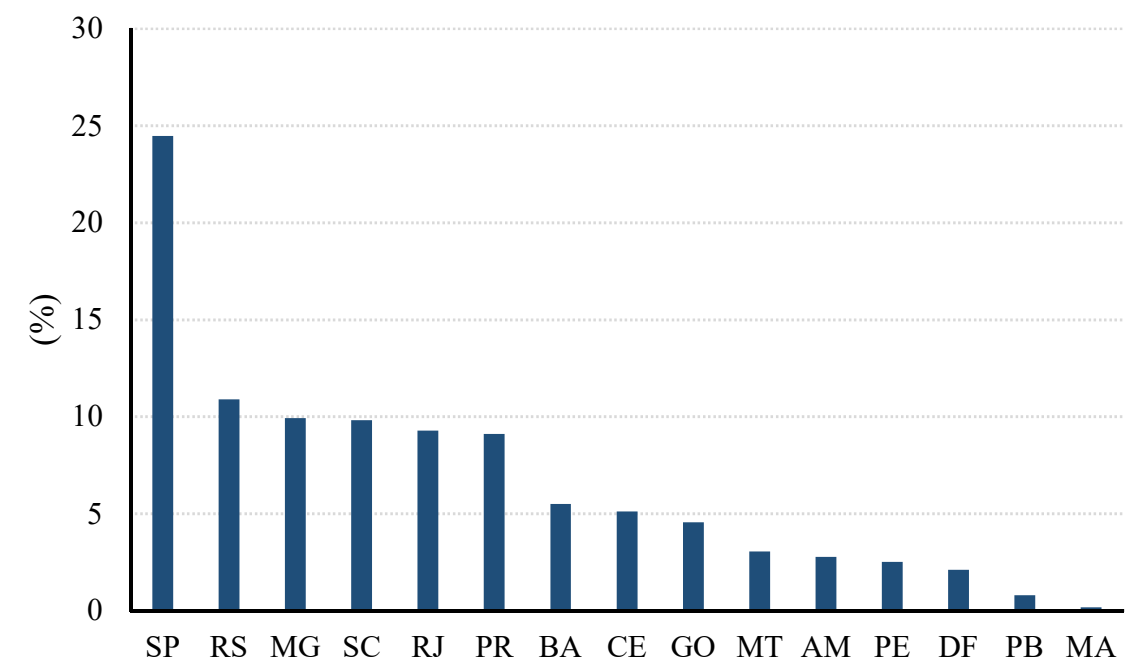

Fonte: Elaboração própria, dados da pesquisa (2017).

A distribuição das firmas por tamanho, em número de empregados, é apresentada na Figura 4. Constata-se que a maioria das firmas são de pequeno ou médio porte, sendo aproximadamente um quinto da amostra composta por firmas consideradas de grande escala de produção, ou seja, com 100 ou mais empregados. A produtividade das firmas pode apresentar uma relação positiva com a escala de produção; os dados mostram que as firmas maiores são mais produtivas (ver anexo, Figura A1), sendo que as firmas grandes registraram, em média, produtividade $5,4 \%$ superior às firmas pequenas e $3,3 \%$ superior às firmas de porte médio.

Figura 4 - Distribuição (\%) das firmas por tamanho ( ${ }^{0}$ de empregados)

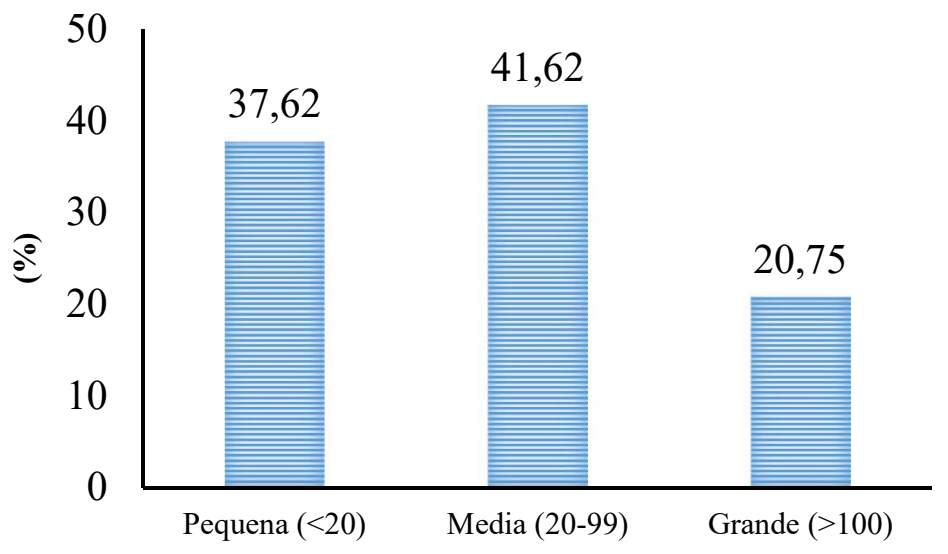

Fonte: Elaboração própria, dados da pesquisa (2017). 
Na Figura 5, pode-se observar a distribuição da produtividade das firmas em dois grupos: as domésticas, que são empresas com capital nacional, e as firmas consideradas estrangeiras (IED), que têm no mínimo $10 \%$ da estrutura do seu capital de propriedade de estrangeiros. Destaca-se a diferença nos níveis de produtividade dos dois grupos, sendo as firmas estrangeiras com nível médio de produtividade $12,6 \%$ superior às domésticas. Isso pode indicar para um possível impacto positivo no desempenho das firmas brasileiras, em geral, originado quando aumenta a integração internacional da economia.

\section{Figura 5 - Distribuição da produtividade (Ln) das firmas: domésticas e estrangeiras}

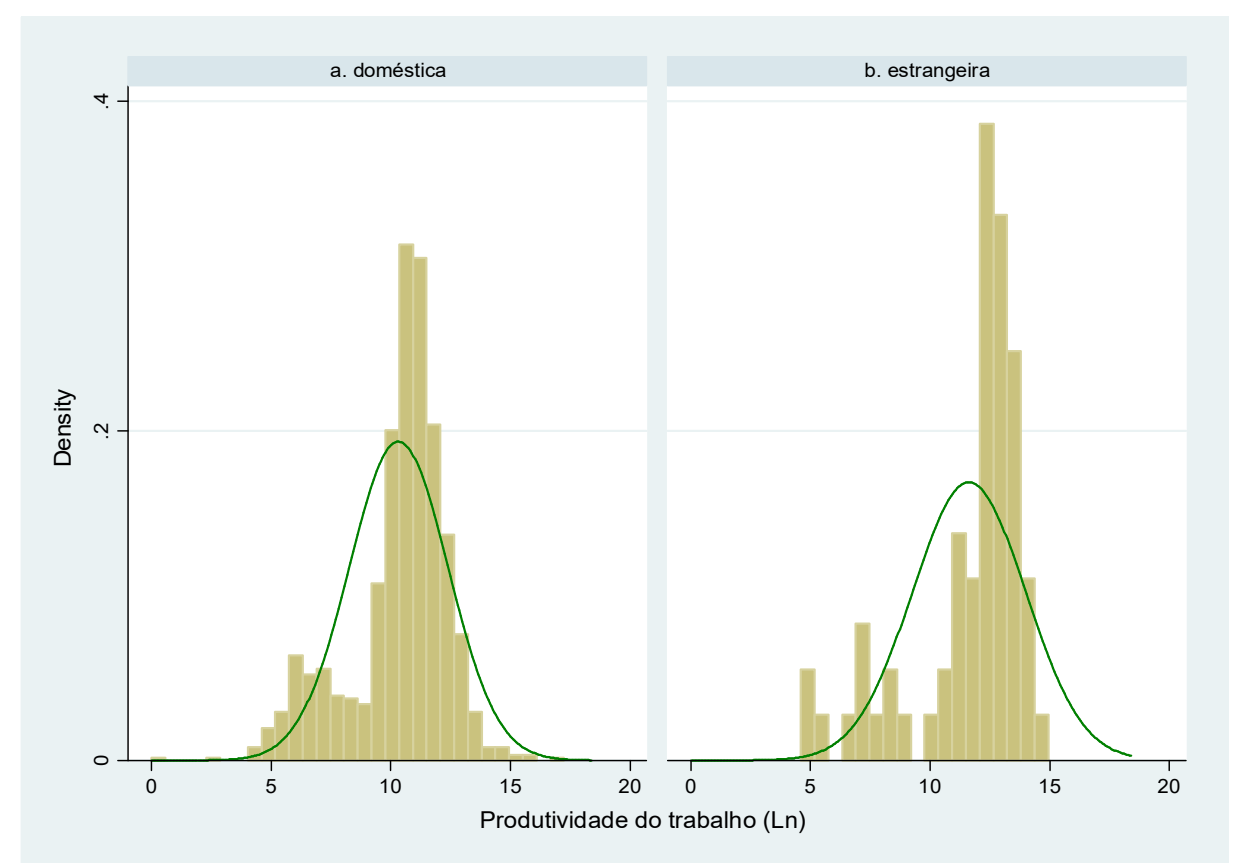

Fonte: Elaboração própria, dados da pesquisa (2017).

Nesta seção, buscou-se fazer uma apresentação descritiva geral e pôde-se especular sobre possíveis relações entre desempenho econômico das firmas com outras variáveis de interesse como, por exemplo, investimento estrangeiro direto. Na próxima seção, aprofunda-se a análise visando estimar possíveis impactos das variáveis de clima de negócio e integração internacional sobre o desempenho das firmas. 


\section{Análise empírica}

Para alcançar o objetivo proposto, será usado um modelo empírico para estimar os impactos das medidas do ambiente de negócios e integração internacional sobre o desempenho das firmas. O modelo empírico proposto é baseado em Hallward-Driemeier et al., (2006) e representado pela Equação 1:

$$
y_{i t}=\alpha+\beta_{1} x_{i t}+\beta_{2} i i_{i t}+\beta_{3} a n_{i t}+\mu_{s}+\mu_{l}+\varepsilon_{i t}
$$

em que a variável $y$ representa o desempenho das firmas, para tanto, usa-se três medidas: produtividade do trabalho, crescimento do emprego e das vendas totais da firma; ii representa as variáveis de integração internacional (IED e finput); an é o conjunto das medidas de ambiente de negócios que são: finanças, infraestrutura física, desembaraço aduaneiro; $x$ representa um conjunto de variáveis de controle, por exemplo, característica individual das firmas como idade e escala de produção; sendo $\mu_{s}, \mu_{l}$ os efeitos fixos não observáveis dos setores e localidade; e $\varepsilon_{i t}$ é o termo de erro.

Como os indicadores de acesso financeiro e infraestrutura física possuem mais de uma medida e são similares, serão construídos índices mediante o procedimento de análise dos componentes principais (PCA). Por meio do PCA, pode-se obter um índice que representa todas as variáveis relacionadas ao acesso financeiro dos agentes econômicos nas respectivas localidades.

Um potencial problema na análise com as variáveis de ambiente de negócio é a endogeneidade. Esse problema pode surgir com uma possível causalidade reversa (HALLWARD-DRIEMEIER et al., 2006). Por exemplo, algumas localidades/regiões, para atrair mais investimentos, podem melhorar o ambiente para fazer negócios e, com isso, receber mais empresas, incluindo empresas multinacionais que tendem a ser mais eficientes. Esse problema é mitigado de algumas maneiras: primeiro, com o uso de uma variável de aglomeração que é representada pelo número de empresas multinacionais em cada setor e localidade, respectivamente; segundo, usar a média local-setor da variável endógena como instrumento, conforme Kinda (2010), no caso da variável finance, utiliza-se também dummy se as demonstrações financeiras da firma foram ou não auditadas por auditor externo; e terceiro, a inclusão de dummy para setores e localidade na regressão ajudará controlar os efeitos de âmbito macro que afetam as variáveis de ambiente de negócios e a firma. 


\subsection{Estimativas e resultados}

Os resultados das estimativas OLS do modelo empírico apresentado na equação 1 estão na Tabela 1. Os efeitos das características das firmas e os efeitos controlados pela dummy de local e setor são apresentados nas duas primeiras colunas (estimativas 1 e 2). No que se refere às características das firmas, constatase que a variável idade, que capta o background da firma em determinado setor e região, mostrou-se relevante para o desempenho. O tamanho, proxy para escala, das firmas não se mostrou estatisticamente significante para afetar o desempenho.

A variável IED é uma dummy que considera se determinada firma tem ou não participação estrangeira na estrutura do capital, e representa integração internacional da firma. O coeficiente apresentado é estatisticamente significante e, portanto, esse resultado implica que as firmas consideradas IED apresentam melhor desempenho econômico - representado pela produtividade do trabalho - em comparação com as firmas em que o capital é nacional. Esse resultado está em linha com a literatura empírica, por exemplo, Hallward-Driemeier et al. (2006) e Borin e Mancini (2016).

\section{Tabela 1 - Os efeitos das características das firmas e integração internacional. Dependente: Produtividade (Ln)}

\begin{tabular}{|c|c|c|c|c|c|}
\hline Variável & (1) & (2) & (3) & (4) & (5) \\
\hline \multirow[t]{2}{*}{ idade } & $0,222 * *$ & $0,202^{*}$ & $0,280 * *$ & $0,381 * * *$ & $0,368 * * *$ \\
\hline & $(0,103)$ & $(0,103)$ & $(0,113)$ & $(0,118)$ & $(0,118)$ \\
\hline \multirow[t]{2}{*}{ média } & 0,211 & $0,227^{\mathrm{a}}$ & 0,229 & $0,273^{a}$ & 0,251 \\
\hline & $(0,145)$ & $(0,145)$ & $(0,167)$ & $(0,173)$ & $(0,174)$ \\
\hline \multirow{2}{*}{ grande } & 0,216 & 0,250 & 0,170 & 0,174 & 0,162 \\
\hline & $(0,213)$ & $(0,214)$ & $(0,243)$ & $(0,246)$ & $(0,246)$ \\
\hline \multirow[t]{2}{*}{ IED } & $0,799 * * *$ & $0,662 * *$ & $0,605^{*}$ & $0,615^{*}$ & $0,580^{*}$ \\
\hline & $(0,298)$ & $(0,292)$ & $(0,319)$ & $(0,341)$ & $(0,349)$ \\
\hline finput & & & & & $\begin{array}{c}0,00203 \\
(0,00359)\end{array}$ \\
\hline \multirow[t]{2}{*}{ aglomera } & & & 0,00431 & $0,0118 * * *$ & $0,0116 * * *$ \\
\hline & & & $(0,00676)$ & $(0,00408)$ & $(0,00411)$ \\
\hline $\mathrm{h}$ _inadeq & & & $\begin{array}{l}-0,0175 \\
(0,0146)\end{array}$ & $\begin{array}{l}-0,0131 \\
(0,0152)\end{array}$ & $\begin{array}{l}-0,0121 \\
(0,0153)\end{array}$ \\
\hline dummy UF & Sim & Sim & Sim & Não & Não \\
\hline dummy setor & Não & Sim & Sim & Sim & Sim \\
\hline constante & $\begin{array}{c}9,543 * * * \\
(1,318)\end{array}$ & $\begin{array}{c}9,521 * * * \\
(1,336)\end{array}$ & $\begin{array}{c}10,85^{* * *} * \\
(0,450)\end{array}$ & $\begin{array}{c}9,191 * * * \\
(0,457)\end{array}$ & $\begin{array}{c}9,189 * * * \\
(0,462)\end{array}$ \\
\hline obs & 850 & 850 & 712 & 712 & 711 \\
\hline
\end{tabular}

Notas: ${ }^{* * *}$ significante a $1 \%,{ }^{* *}$ significante a $5 \%,{ }^{*}$ significante a $10 \%,{ }^{a}$ significante a $11 \%$. Errospadrão entre parênteses corrigidos para heterocedasticidade pelo procedimento de White.

Fonte: Elaboração própria. 
Nas estimativas (3) a (5), passou-se a considerar os efeitos da variável aglomeração ( $\mathrm{n}^{\mathrm{o}}$ de empresas estrangeiras em dado setor e região específica), sendo que, nas duas últimas colunas, não há o controle da dummy de localização (UF), isso porque a variável aglomeração objetiva captar a atratividade local. Essa variável também pode captar os efeitos spillovers da presença de firmas IED em certo setor e local. Os resultados são estatisticamente significantes (colunas 4 e 5), demonstrando que firmas com vizinhos que têm participação estrangeira tendem a apresentar melhor desempenho em termos de produtividade. A variável que representa a inadequação da força de trabalho (h_inadeq), que é o terceiro maior obstáculo na indicação das empresas, embora tenha apresentado sinal esperado, não se mostrou como estatisticamente significante ao nível convencional. Esse resultado decorre da proxy utilizada, razão entre trabalhadores não qualificados em relação aos qualificados, é provável que essa medida não conseguiu capturar o efeito desse obstáculo.

O segundo bloco de variáveis de interesse são as representantes do ambiente de negócios (an). Na Tabela 2, constam as estimativas considerando as variáveis que representam o ambiente de negócios conforme a literatura desse campo (DOLLAR et al., 2006; HALLWARD-DRIEMEIER et al., 2006; KINDA, 2010). Adicionalmente, apresenta-se estimativa com uma variável alternativa, taxa de crescimento do emprego, como medida de desempenho das firmas.

As estimativas com a inclusão das proxies para o ambiente de negócios mostram uma certa instabilidade dos parâmetros diante da mudança na especificação. Observa-se que a variável idade muda de sinal com a mudança de especificação. Quanto à variável tamanho, a estimativa (2) sugere que o tamanho da firma importa quando se trata de desempenho. As variáveis sobre ambiente de negócios mostram que reduzir o número médio de dias para importar (dimp) pode contribuir para o aumento de desempenho. Já a variável infraestrutura, que tem como proxy o número de dias de estoque do insumo mais importante, apresentou sinal positivo indicando que as firmas que possuem mais estoque tendem a registrar maior desempenho. Isso pode indicar que o sistema de infraestrutura logística não funciona bem como poderia. 
Tabela 2 - Os efeitos das características das firmas e ambiente de negócios. Dependente: Produtividade (Ln) e taxa de crescimento do emprego

\begin{tabular}{|c|c|c|c|c|}
\hline \multirow[t]{2}{*}{ Variável } & \multicolumn{2}{|c|}{ Produtividade } & \multicolumn{2}{|c|}{$\begin{array}{c}\text { Taxa de crescimento } \\
\text { do emprego }\end{array}$} \\
\hline & (1) & (2) & (3) & (4) \\
\hline \multirow[t]{2}{*}{ idade } & 0,155 & 0,0861 & $0,333 * * *$ & $-0,260 * * *$ \\
\hline & $(0,327)$ & $(0,0864)$ & $(0,111)$ & $(0,0936)$ \\
\hline \multirow[t]{2}{*}{ média } & 1,017 & $0,203^{\mathrm{a}}$ & 0,0993 & 0,132 \\
\hline & $(0,887)$ & $(0,129)$ & $(0,591)$ & $(0,147)$ \\
\hline \multirow[t]{2}{*}{ grande } & 0,393 & $0,404 * *$ & 0,299 & 0,212 \\
\hline & $(0,967)$ & $(0,172)$ & $(1,085)$ & $(0,132)$ \\
\hline \multirow[t]{2}{*}{ IED } & $-0,0930$ & & & \\
\hline & $(0,444)$ & & & \\
\hline \multirow[t]{2}{*}{$\operatorname{dimp}$} & $-0,0189^{*}$ & & & \\
\hline & $(0,0105)$ & & & \\
\hline infraestrutura & & $\begin{array}{l}0,00334 * * \\
(0,00133)\end{array}$ & & \\
\hline finance & & & $\begin{array}{l}-0,324 \\
(1,478)\end{array}$ & \\
\hline \multirow[t]{2}{*}{ finput } & & & 0,00301 & 0,00305 \\
\hline & & & $(0,00382)$ & $(0,00208)$ \\
\hline \multirow[t]{2}{*}{$\mathrm{h}$ _inadeq } & & & & $-0,00626^{*}$ \\
\hline & & & & $(0,00374)$ \\
\hline \multirow[t]{2}{*}{ export } & & & & $-0,0736$ \\
\hline & & & & $(0,0497)$ \\
\hline \multirow[t]{2}{*}{ aglomera } & & & & 0,00306 \\
\hline & & & & $(0,00435)$ \\
\hline dummy de UF & Sim & Sim & Sim & Sim \\
\hline dummy setor & Sim & Sim & Sim & Sim \\
\hline \multirow[t]{2}{*}{ constante } & $8,249 * * *$ & $8,350 * * *$ & $9,091 * * *$ & 0,481 \\
\hline & $(1,358)$ & $(1,950)$ & $(1,368)$ & $(0,387)$ \\
\hline obs & 155 & 1.064 & 745 & 1.129 \\
\hline
\end{tabular}

A variável que busca capturar as condições da oferta de mão de obra adequada (h_inadeq), e é o terceiro item que o maior número de empresas indica como um obstáculo para os negócios, apresentou sinal esperado e é estatisticamente significante. Esse resultado mostra que força de trabalho qualificada pode contribuir para melhor desempenho das firmas.

Em suma, os resultados aqui apresentados estão em linha com a literatura ${ }^{6}$ e mostram que, controlando as características das firmas e os efeitos fixos de setor

${ }^{6}$ Ver Dethier et al. (2010) para uma discussão detalhada e uma survey da literatura. 
e localidade/UF, maior integração internacional permite melhor desempenho das firmas brasileiras. Quanto ao ambiente de negócios, os resultados mostram que nem todas as variáveis são estatisticamente significantes, mas mostram que melhorar o desembaraço para o comércio internacional, mediante a redução do tempo para importar, melhora o desempenho das firmas. A proxy para infraestrutura e qualidade da mão de obra também se mostraram estatisticamente significantes para afetar o desempenho econômico.

\section{Considerações finais}

Usando um conjunto de dados desagregado de 1.802 firmas que atuam em 15 diferentes localidades no Brasil, a presente pesquisa analisa como a integração internacional e o ambiente de negócios afetam o desempenho das firmas. Os resultados indicam que tanto a integração internacional quanto o ambiente de negócios podem contribuir para a performance das firmas brasileiras, e reforça a importância dos dados em nível de firmas para explorar esses efeitos.

Pesquisas relacionadas ao ambiente de negócios com dados em nível de firmas só se tornaram possíveis a partir da última década "graças" ao esforço do Banco Mundial para realização das surveys.

Os resultados indicam que, em geral, o desempenho das firmas que atuam no Brasil está correlacionado com participação estrangeira na estrutura de capital das firmas, background no mercado e disponibilidade de estoques. Também, locais com melhor ambiente de negócios, representados por menor tempo para importar e oferta qualificada de mão de obra, além da existência de aglomerados de empresas estrangeiras, melhoram o desempenho da firma. Entender o desempenho das firmas é de grande importância para a formulação de políticas para o desenvolvimento econômico, e as análises a partir dos dados em nível de firmas são essenciais. Esses resultados devem ser interpretados de forma cuidadosa, principalmente porque é escassa a literatura brasileira nesse tópico, e, como pesquisas futuras, devem-se aprofundar no entendimento e construção de variáveis adicionais que representam o ambiente de negócios. 


\section{Referências}

ALFARO, L.; KALEMLI-OZCAN, S.; SAYEK, S. FDI, Productivity and Financial Development. The Word Economy, v. 32, n. 1, p. 111-135, 2009.

BAS, M. Input-trade liberalization and firm export decisions: Evidence from Argentina. Journal of Development Economics, v. 97, n. 2, p. 481-493, 2012.

BORIN, A.; Mancini, M. Foreign direct investment and firm performance: an empirical analysis of Italian firms. Review of World Economics, v. 152, n. 4, p. 705-732, 2016.

CAMERON, A. C.; TRIVEDI, P. K. Microeconometrics: methods and applications. Cambridge University Press, 2005.

CASTELLANI, D.; GIOVANNETTI, G. Productivity and the international firm: dissecting heterogeneity. Journal of Economic Policy Reform, v. 13, n. 1, p. 2542, 2010.

CORCORAN, A.; GILLANDERS, R. Foreign direct investment and the ease of doing business. Review of World Economics, v. 151, n. 1, p. 103-126, 2015.

DETHIER, J. J.; HIRN, M.; STRAUB, S. Explaining enterprise performance in developing countries with business climate survey data. The World Bank Research Observer, v. 26, n. 2, p. 258-309, 2011.

DOLLAR, D.; HALLWARD-DRIEMEIER, M.; MENGISTAE, T. Investment climate and international integration. World Development, v. 34, n. 9, p. 14981516, 2006.

FERREIRA, P. C.; GUILLÉN, O. T. Estrutura competitiva, produtividade industrial e liberalização comercial no Brasil. Revista Brasileira de Economia. v. 58, n. 4, p. 507-532, 2004.

HALLWARD-DRIEMEIER, M.; WALLSTEN, S.; XU， L. C. Ownership, investment climate and firm performance. Economics of Transition, v. 14, n. 4, p. 629-647, 2006.

JAVORCIK, B. S. Does foreign direct investment increase the productivity of domestic firms? Is search of spillovers through backward linkages. American Economic Review, v. 94, n. 3, p. 605-627, 2004.

KINDA, T. Investment climate and FDI in developing countries: firm-level evidence. World development, v. 38, n. 4, p. 498-513, 2010. 
KINDA, T.; PLANE, P.; VÉGANZONÈS-VAROUDAKIS, M. A. Firm productivity and investment climate in developing countries: how does Middle East and North Africa manufacturing perform? The Developing Economies, v. 49, n. 4, p. 429-462, 2011.

SEKKAT, K.; VEGANZONES-VAROUDAKIS, M. A. Openness, investment climate, and FDI in developing countries. Review of Development Economics, v. 11, n. 4, p. 607-620, 2007.

WAGNER, J. Exports and productivity: A survey of the evidence from firm-level data. The World Economy, v. 30, n. 1, p. 60-82, 2007.

WALDKIRCH, A. Foreign Ownership and Firm Productivity: Evidence from a Large Sample of Countries. mimeo., 2015.

WORLD BANK. Enterprise Surveys. Washington-DC: The World Bank, 2016.

XU, L. C. The effects of business environments on development: Surveying new firm-level evidence. The World Bank Research Observer, v. 26, n. 2, p. 310-340, 2011 . 


\section{Anexos}

Tabela A1. Variáveis utilizadas no estudo.

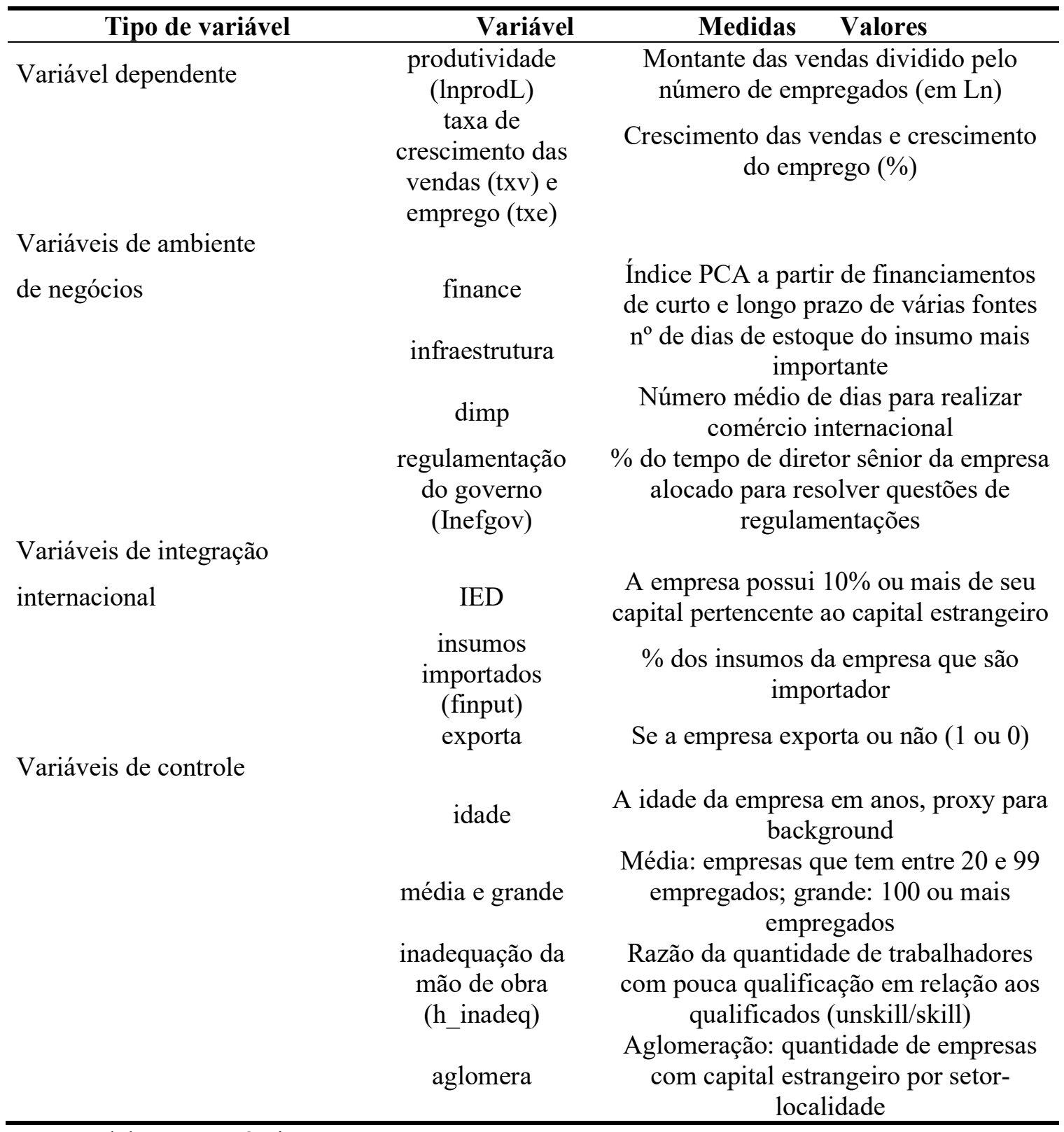

Fonte: Elaboração própria. 
Tabela A2 - Estatística descritiva das variáveis

\begin{tabular}{lcr}
\hline \multicolumn{1}{c}{ Variável } & Média & Desvio \\
\hline inprodL & 10,50 & 2,03 \\
idade & 21,72 & 16,53 \\
média & 0,42 & 0,49 \\
grande & 0,21 & 0,41 \\
h_inadeq & 1,30 & 3,91 \\
fdi & 0,06 & 0,23 \\
finput & 13,02 & 22,55 \\
aglomera & 27,21 & 22,63 \\
finance & 0,21 & 1,33 \\
infraestrutura & 24,44 & 34,44 \\
inefgov & 19,38 & 21,00 \\
txv & 0,15 & 0,39 \\
txe & 0,18 & 1,72 \\
dexp & 15,87 & 19,71 \\
dimp & 21,93 & 24,09 \\
\hline
\end{tabular}

Fonte: Elaboração própria. 
Tabela A3 - Desempenho das firmas: média e desvio padrão por localidade

\begin{tabular}{|c|c|c|c|}
\hline Localização & $\begin{array}{c}\text { Produtividade } \\
\text { do trabalho } \\
\text { (InprodL) } \\
\end{array}$ & $\begin{array}{l}\text { Crescimento das } \\
\text { vendas (txv) }\end{array}$ & $\begin{array}{l}\text { Crescimento do } \\
\text { emprego (txe) }\end{array}$ \\
\hline \multirow[t]{2}{*}{ Amazonas } & 10,59 & 0,22 & $-0,22$ \\
\hline & $(1,53)$ & $(0,33)$ & $(2,57)$ \\
\hline \multirow[t]{2}{*}{ Bahia } & 10,77 & 0,15 & $-0,15$ \\
\hline & $(1,60)$ & $(0,25)$ & $(3,39)$ \\
\hline \multirow[t]{2}{*}{ Brasília (DF) } & 10,23 & 0,09 & 0,47 \\
\hline & $(2,22)$ & $(0,51)$ & $(2,44)$ \\
\hline \multirow[t]{2}{*}{ Ceará } & 10,04 & 0,18 & 0,28 \\
\hline & $(1,91)$ & $(0,44)$ & $(1,72)$ \\
\hline \multirow[t]{2}{*}{ Goiás } & 10,23 & 0,05 & 0,09 \\
\hline & $(2,39)$ & $(0,52)$ & $(2,04)$ \\
\hline \multirow[t]{2}{*}{ Maranhão } & 10,40 & 0,04 & 0,85 \\
\hline & $(0,71)$ & & $(0,84)$ \\
\hline \multirow[t]{2}{*}{ Mato Grosso } & 9,74 & 0,01 & 0,53 \\
\hline & $(2,21)$ & $(0,54)$ & $(4,14)$ \\
\hline \multirow[t]{2}{*}{ Minas Gerais } & 8,32 & 0,18 & 0,04 \\
\hline & $(2,46)$ & $(0,38)$ & $(1,06)$ \\
\hline \multirow[t]{2}{*}{ Paraíba } & 10,36 & 0,20 & 0,20 \\
\hline & $(0,54)$ & $(0,34)$ & $(0,48)$ \\
\hline \multirow[t]{2}{*}{ Paraná } & 10,81 & 0,17 & 0,16 \\
\hline & $(1,73)$ & $(0,42)$ & $(2,51)$ \\
\hline \multirow[t]{2}{*}{ Pernambuco } & 10,45 & 0,08 & 0,26 \\
\hline & $(1,50)$ & $(0,40)$ & $(0,47)$ \\
\hline \multirow[t]{2}{*}{ Rio Grande do Sul } & 10,89 & 0,20 & 0,18 \\
\hline & $(1,68)$ & $(0,34)$ & $(0,77)$ \\
\hline \multirow[t]{2}{*}{ Rio de Janeiro } & 10,55 & 0,11 & 0,18 \\
\hline & $(1,92)$ & $(0,39)$ & $(0,98)$ \\
\hline \multirow[t]{2}{*}{ Santa Catarina } & 10,95 & 0,18 & 0,36 \\
\hline & $(1,33)$ & $(0,29)$ & $(1,53)$ \\
\hline \multirow[t]{2}{*}{ São Paulo } & 11,10 & 0,13 & 0,20 \\
\hline & $(1,83)$ & $(0,40)$ & $(0,60)$ \\
\hline
\end{tabular}

Nota: Desvio padrão entre parênteses.

Fonte: Elaboração própria 
Figura A1 - Produtividade por tamanho ( $n^{0}$ de empregados) das empresas

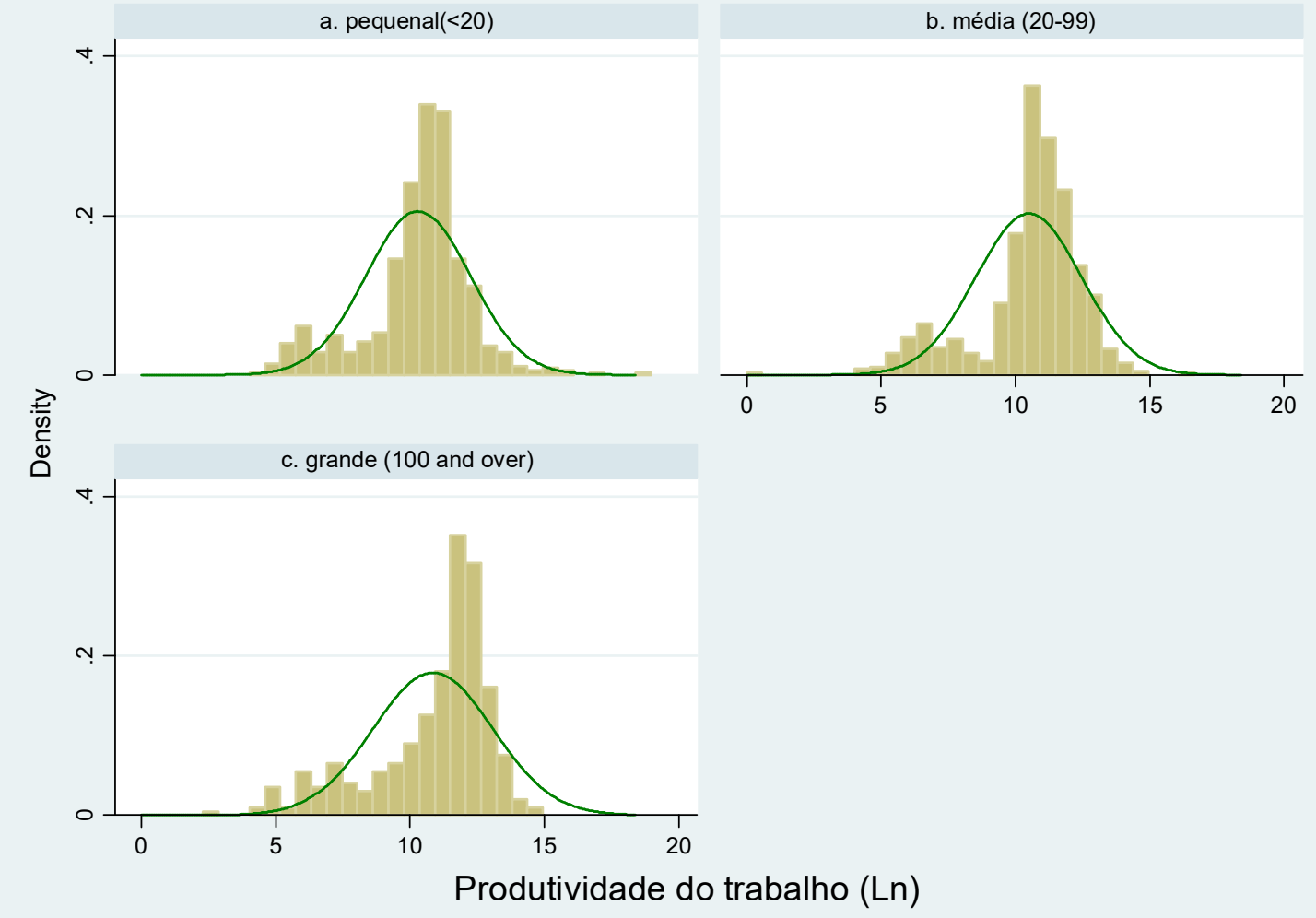

Fonte: Elaboração própria. 